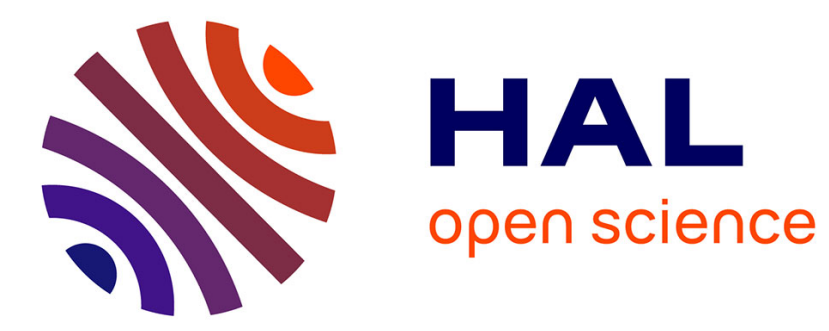

\title{
Interplay of spin-orbit coupling and lattice distortion in metal substituted 3D tri-chloride hybrid perovskites
}

Claudine Katan, Laurent Pedesseau, Mikäl Kepenekian, Alain Rolland, Jacky Even

\section{- To cite this version:}

Claudine Katan, Laurent Pedesseau, Mikaël Kepenekian, Alain Rolland, Jacky Even. Interplay of spinorbit coupling and lattice distortion in metal substituted 3D tri-chloride hybrid perovskites. Journal of Materials Chemistry A, 2015, Perovskite Solar Cells, 3 (17), pp.9232-9240. 10.1039/C4TA06418F . hal-01103517v2

\section{HAL Id: hal-01103517}

https://hal-univ-rennes1.archives-ouvertes.fr/hal-01103517v2

Submitted on 25 Nov 2016

HAL is a multi-disciplinary open access archive for the deposit and dissemination of scientific research documents, whether they are published or not. The documents may come from teaching and research institutions in France or abroad, or from public or private research centers.
L'archive ouverte pluridisciplinaire HAL, est destinée au dépôt et à la diffusion de documents scientifiques de niveau recherche, publiés ou non, émanant des établissements d'enseignement et de recherche français ou étrangers, des laboratoires publics ou privés.

$$
\text { Copyright }
$$




\title{
Interplay of spin-orbit coupling and lattice distortion in metal substituted 3D tri-chloride hybrid perovskites.
}

\author{
C. $\operatorname{Katan}^{* a}$, L. Pedesseau ${ }^{b}$, M. Kepenekian ${ }^{a}$, A. Rolland ${ }^{b}$, and J. Even ${ }^{* b}$
}

Within the scope of this 'Perovskite Solar Cells' themed issue, following their rise to superstardom for photovoltaics, we herein begin by recalling a couple of pioneering works and basic concepts useful to rationalize structure-property relationships and already gained by several decades of active research on hybrid perovskite materials. Effects of band folding and octahedral tilting related to structural phase transitions are given particular emphasis. Next, we investigate theoretically metal substitution based on available crystallographic data of the tri-chloride $\mathrm{CH}_{3} \mathrm{NH}_{3} \mathrm{MCl}_{3}(\mathrm{M}=\mathrm{Pb}, \mathrm{Sn}, \mathrm{Ge})$ crystal structures, having a 3D inorganic network of corner-shared octahedra. In fact, both the chlorine-based hybrid perovskites and metal substitution have not received much attention from materials science theoreticians. Moreover, metal substitution leads to additional crystal structure diversity with formation of pyramidal $\mathrm{MCl}_{3}{ }^{-}$ions. Distinct focus is paid to their optoelectronic properties, especially band-gap and absorption. Moreover, investigation of bromides and iodides analogues reveals that spin-orbit interaction stemming from halogens may also be significant, especially for iodine. This can be analysed from the atomic charges calculated through the Atom In Molecules (AIM) quantum theory.

\section{Introduction}

The breakthrough achieved by hybrid perovskites for solar cells outlined in this special issue is undeniable. However, since 2013 it is generally recognized that there is an urgent need for fundamental understanding to unravel what makes them so successful. This is of particular relevance in the hope of undoing technological locks so as to plan industrialization of low-cost devices built around organic-inorganic perovskites. In fact, currently, most of the research effort still sticks to 3D organohalide lead perovskites that faces possible stability problems towards heat/moisture. ${ }^{1}$ Moreover, the presence of lead might be a problem with respect to future government directives on the use of hazardous substances in electric and electronic equipment, even so the percentage of lead would be low in a solar panel as compared to a car battery. It may even turn into an opportunity for recycling not only car batteries ${ }^{2}$ but also other manufactured goods such as our old TV and computer screens. The few attempts made with tin show yet inconclusive results both in terms of efficiency and stability.,

On the other hand, the room for chemical substitution is huge already within the class of pure $\mathrm{AMX}_{3}$ perovskites, where in the context of formal charges $\mathrm{A}$ is an inorganic or organic cation $\left(\mathrm{A}=\mathrm{CH}_{3} \mathrm{NH}_{3}{ }^{+}\right.$for the most famous hybrid perovskites), $\mathrm{M}$ an inorganic dication (in this case, $\mathrm{Pb}^{2+}$ ) and $\mathrm{X}$ an inorganic anion (in this case, $\mathrm{I}^{-}$). This composition leads to a cornershared 3D network of $\left(\mathrm{MX}_{6}\right)^{4-}$ octahedra. Besides, varying while controlling the stoichiometric ratio affords crystal packing with other dimensionalities from layered inorganic sheets (2D) up to isolated inorganic octahedrons (0D). ${ }^{5-7}$ For instance, in the context of solar cells, H. I. Karunadasa and coworkers have recently demonstrated that layered hybrid perovskites can also provide effective solar-cell absorbers with enhanced moisture stability. ${ }^{8}$ Thus, in view of the large number of opportunities in chemical engineering, a better understanding of underlying mechanisms is of paramount importance. In this context, many computational chemists and physicists over the world have started to take up the challenge. However, the know-how gained by several decades of active research in the field of hybrid perovskites must be carefully considered.

In fact, before the perovskites boom for solar cells, such materials have been the subjects of many studies for several decades. The last ten years have witnessed exciting work especially on self-assembled hybrid organic layered perovskites. This was prompt by their technological potentialities for optoelectronic applications such as transistor $^{9,10}$ and light emitting ${ }^{11-14}$ devices. Noteworthy, recent investigations on $3 \mathrm{D}$ hybrid perovskites also revealed their potential for light emitting devices. ${ }^{15-17}$ Even so a general overview of past research on hybrid perovskites is beyond the scope of this paper, we underline the pioneering work of $\mathrm{G}$. Papavassiliou $^{5,13,18}$ and D. Mitzi ${ }^{6,19}$ in rationalizing the structure-properties relationship of hybrid perovskites.

This prompts us to start with a first section devoted to a brief summary of key findings and basic concepts on theoretical aspects. This section aims at bridging the gap between concepts of molecular chemistry and solid-state physics. It is particularly useful in the context of a paradigm shift from dye sensitized solar cells to all solid state hybrid devices. ${ }^{20}$ Next, we will investigate metal substitution, considering tin $(\mathrm{M}=\mathrm{Sn})$ and lead

\section{J. Mater. Chem. A, 2015, 3, 9232-9240; DOI: 10.1039/C4TA06418F}


$(\mathrm{M}=\mathrm{Pb})$ metals and germanium $(\mathrm{M}=\mathrm{Ge})$ metalloid, in chlorinebased hybrid perovskites that have yet received much less theoretical attention than their iodine or bromine counterparts. Special attention will be paid to structural distortions, to spinorbit interactions stemming both from metals and halogens and results will be discussed in the light of atomic data.

\section{Computational Methods}

Calculations were performed using crystal structures available from the Cambridge structural database (CSD). ${ }^{21}$ The following crystal structures have been investigated: $\mathrm{CH}_{3} \mathrm{NH}_{3} \mathrm{GeCl}_{3}$ from ref [22] with Pnma and $\mathrm{Pm} \overline{3} \mathrm{~m}$ phases collected on deuteriated samples by neutron diffraction at 250 and $475 \mathrm{~K}$, respectively; $\mathrm{CH}_{3} \mathrm{NH}_{3} \mathrm{SnCl}_{3}$ from ref [23] with $\mathrm{Pc}$ and $\mathrm{Pm} \overline{3} \mathrm{~m}$ phases collected from powder X-Ray diffraction at 318 and $478 \mathrm{~K}$, respectively; $\mathrm{CH}_{3} \mathrm{NH}_{3} \mathrm{PbCl}_{3}$ from ref [24] with $\mathrm{Pm} \overline{3} \mathrm{~m}$ phase above $190 \mathrm{~K}$ and Pnma phase at $80 \mathrm{~K}$ obtained from neutron and synchrotron diffraction; $\mathrm{CH}_{3} \mathrm{NH}_{3} \mathrm{PbBr}_{3}$ Pnma phase collected on deuteriated powders by neutron diffraction at $11 \mathrm{~K}$ from ref. [25]; $\mathrm{CH}_{3} \mathrm{NH}_{3} \mathrm{PbI}_{3}$ from ref. [26] for the Pnma phase collected from single crystal X-Ray diffraction at $100 \mathrm{~K}$ and from ref. [27] for the $\mathrm{Pm} \overline{3} \mathrm{~m}$ phase from Guinier-Simon photographs of the powdered crystal at $327 \mathrm{~K}$.

Band structures and absorption spectra were computed within the DFT implementation available in the ABINIT package. ${ }^{28}$ The Kohn-Sham DFT model was implemented using the local density approximation (LDA) for exchange-correlation, with relativistic norm-conserving separable dual-space Gaussiantype pseudopotentials of Goedecker, Teter, and Hutter (HGH) Chlorine-based hybrid perovskites may thus provide large band-gap layers for top cell in multijunction heterostructures for all atoms. ${ }^{29}$ In addition to earlier tests on related 3D and 2D hybrids, ${ }^{30,31}$ we have further checked that the DFT band structures near the band-gap do not depend on the inclusion of $d$-orbitals of the metal considering $\left(\mathrm{C}_{4} \mathrm{H}_{9} \mathrm{NH}_{3}\right)_{2} \mathrm{PbI}_{4}$. The electronic wave-functions were expanded onto a plane-wave basis set with an energy cut-off of $680 \mathrm{eV}$ (50 Ry). For reciprocal space integration, $8 \times 8 \times 8$ Monkhorst-Pack grids were used for the Pm3m structures, $4 \times 4 \times 4$ for the Pnma and Pc structures. Calculations were systematically performed with and without spin-orbit coupling (SOC). Operators implemented in ABINIT $^{28}$ with HGH type pseudopotentials ${ }^{29}$ are constructed such that SOC can be selectively been switched off for certain atoms using the so psp keyword. We used this option to investigate $\mathrm{SOC}$ induced by halogen atoms.

Many-body corrections at the $\mathrm{G}_{0} \mathrm{~W}_{0}{ }^{32}$ and self-consistent $\mathrm{GW}^{33}$ levels as well as Bader charge analysis (AIM) ${ }^{34,35}$ have been performed with $\mathrm{VASP}^{36}$ using the projector-augmented wave method $(\mathrm{PAW})^{37}$ with an energy cutoff of $950 \mathrm{eV}$. The Kohn-Sham DFT model was GGA-PBE ${ }^{38}$ for exchangecorrelation. For reciprocal space integration, $8 \times 8 \times 8$ MonkhorstPack grids were used for all investigated $\mathrm{Pm} \overline{3} \mathrm{~m}$ structures as well as for the Pnma structure of $\mathrm{CH}_{3} \mathrm{NH}_{3} \mathrm{PbCl}_{3}$, and $6 \times 8 \times 8$ was chosen for the Pnma structure of $\mathrm{CH}_{3} \mathrm{NH}_{3} \mathrm{GeCl}_{3}$ and the $\mathrm{Pc}$ structure of $\mathrm{CH}_{3} \mathrm{NH}_{3} \mathrm{SnCl}_{3}$. A grid spacing of $\mathrm{ca} 0.4 \AA$ has been used for AIM analysis. ${ }^{35}$

For simulating the high temperature disordered phases, especially the $\operatorname{Pm} \overline{3} \mathrm{~m}$ crystal structures, organic cations have been replaced by $\mathrm{Cs}^{+}$cations located at the nitrogen position. In fact, this procedure has already been checked previously (vide infra) and more recently for $\mathrm{CH}_{3} \mathrm{NH}_{3} \mathrm{PbI}_{3}, \mathrm{CH}_{3} \mathrm{NH}_{3} \mathrm{PbBr}_{3}{ }^{30}$ and was further confirmed for the Pnma phase of $\mathrm{CH}_{3} \mathrm{NH}_{3} \mathrm{PbCl}_{3}{ }^{20}$ Herein, the validity of this approach was also checked for the Pnma crystal structure of $\mathrm{CH}_{3} \mathrm{NH}_{3} \mathrm{GeCl}_{3}$, leading to comparable band structures with and without the methylammonium cation. Given that the positions of the organic part remains unresolved in the crystal structure of the RT Pc phase of $\mathrm{CH}_{3} \mathrm{NH}_{3} \mathrm{SnCl}_{3},{ }^{23} \mathrm{a}$ $\mathrm{Cs}^{+}$cation was used instead. Whenever needed, hydrogen atoms were added following the space group or both N-H and $\mathrm{C}-\mathrm{H}$ bond lengths were stretched to 1.089 and $1.008 \AA$, respectively.

\section{Basic concepts}

As early as in 1994, from extended Hückel tight-binding calculations on a single $(\mathrm{SnI} 4)^{2-}$ layer, Papavassiliou et al. revealed the main features of the band structure of hybrid perovskites, namely a direct band-gap with valence band largely represented by in-plane $p$-orbitals of the halogen atom that undergoes anti-bonding hybridization with the $s$-orbitals of the metal, whereas conduction band arises mainly from $p$ orbitals of the metal. ${ }^{18}$ Since then, many band structure calculations showed that, except for a few specific cases, ${ }^{39}$ the molecular levels of the organic cation contribute far above and below the conduction and valence band, respectively, which allows to recover almost the same band structure by replacing the organic molecules by either a background charge density ${ }^{40}$ or by a set of inorganic ions $\left(e . g . \mathrm{Na}^{+}\right){ }^{41}$

In fact, in most cases the preponderant effect of the cation A is an indirect steric effect (size and symmetry) on the crystal structure and in turn on the band-gap. This can be intuited from atomic orbital hybridization starting with a linear chain as sketched Figure 1, which illustrates that the valence band maximum (VBM) and conduction band minimum (CBM) arise at the Brillouin-Zone (BZ) edge. When the M-X distance increases, the anti-bonding character of VBM decreases, as does the bonding character of CBM resulting in a larger bandgap. The same holds upon deformation of the linear chain. Moreover, this schematic example also illustrates the band folding occurring when the unit cell increases: when the unit cell is doubled the VBM and CBM fold back to the centre of the BZ, namely the $\Gamma$-point (Figure 1). This is further illustrated for the real crystal structures of $\mathrm{CH}_{3} \mathrm{NH}_{3} \mathrm{PbI}_{3}$ in figure 2 so as to emphasis appropriate band labelling and to promote the use of symmetry and related selection rules in the analysis of experimental and theoretical data. 
VB

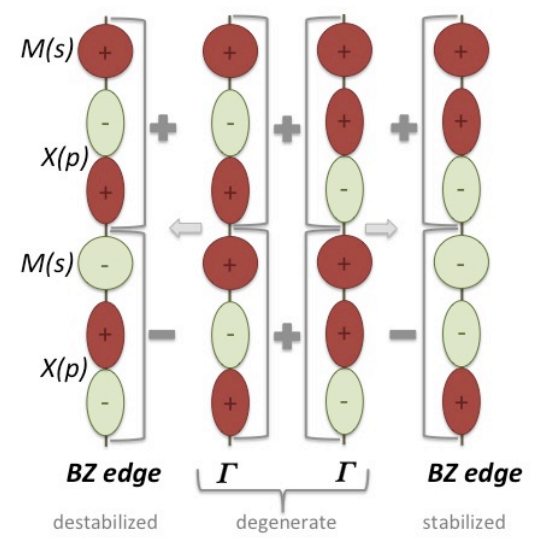

CB

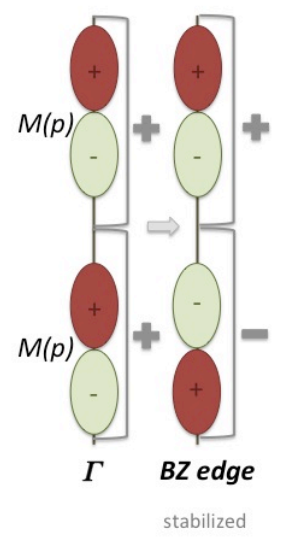

Fig. 1 Atomic orbitals hybridization and band folding in the Brillouin zone (BZ) exemplified on the simplest scenario, which consists of a linear chain. Left panel: hybridization between the $p$-orbitals of the halogen, $X(p)$, and the $s$-orbitals of the metal, $M(s)$. The valence band maximum (VBM) corresponds to the anti-bonding combination (left) that shows up at the BZ edge when the unit cell is build from one halogen and one metal (grey bracket). Upon unit cell doubling in real space (two grey brackets), the two combinations shown left and right fold back to the $\Gamma$ point, centre of the new BZ. Right panel: hybridization between the $p$-orbitals of the metal, $M(p)$. The conduction band minimum (CBM) corresponds to the bonding combination (right) that shows up at the $B Z$ edge when the unit cell is build from one metal (grey bracket). Upon unit cell doubling, this combination folds back to the $\Gamma$ point, centre of the new $B Z$.

Among the structural parameters influencing the band-gap, $\mathrm{M}-\mathrm{X}-\mathrm{M}$ bond angles and $\mathrm{MX}_{6}$ octahedral tilting of $\mathrm{AMX}_{3}$ and $\mathrm{AMX}_{4}$ perovskites have already received much attention. ${ }^{19,42-45}$ For instance, based on extended Hückel tight-binding calculations and spectroscopic data of a series of $\left[\mathrm{R}-\mathrm{NH}_{3}\right]_{2} \mathrm{SnI}_{4}$ layered perovskites, J. L. Knutson, J. D. Martin and D. B. Mitzi demonstrated that "the Sn-I-Sn bond angle is the dominant structural factor that controls the variation in the band-gap". ${ }^{19}$ Borriello et al. further investigated theoretically structureproperty relationship on tin-halide $3 \mathrm{D}$ perovskites with structural variation of the corner-sharing octahedra network based on available experimental structures and DFT optimization. $^{46}$ More recently, De Angelis and co-workers carefully investigated how the electronic structure (band-gap, effective masses) changes with the octahedral tilting using a model tetragonal $\left[\mathrm{CsPbI}_{3}\right]_{4}{ }^{45}$ In particular, the later study reveals an enhancement of the spin-orbit coupling due to structure modifications. The effect coincides with an enhancement of the ionic character of the $\mathrm{Pb}-\mathrm{I}$ bonds.

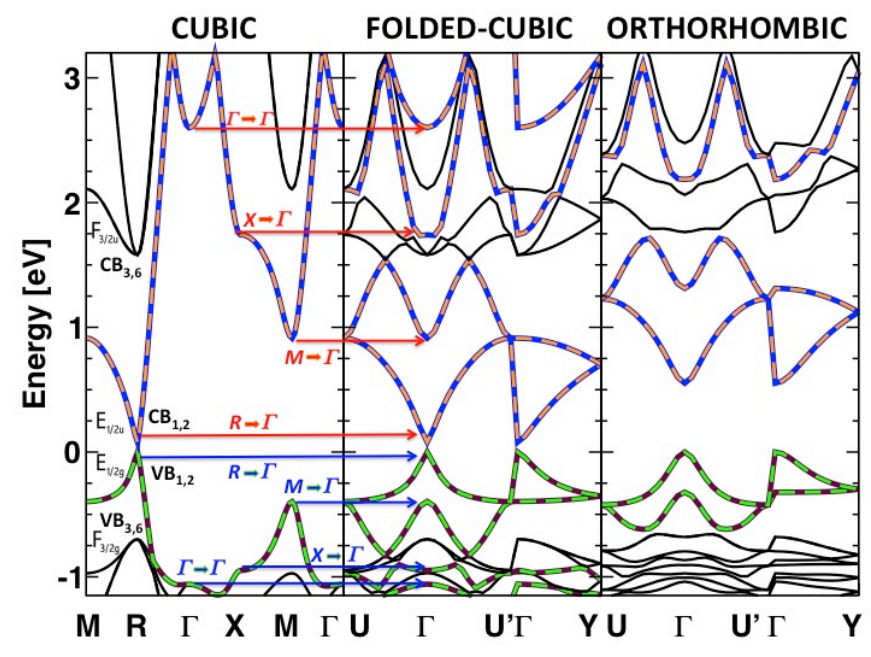

Fig. 2 Band folding in the Brillouin zone (BZ) shown for $\mathrm{CH}_{3} \mathrm{NH}_{3} \mathrm{Pbl}_{3}$ with DFT calculations including spin-orbit coupling (SOC). Left panel: electronic band diagram calculated for the cubic $\operatorname{Pm} \overline{3} \mathrm{~m}$ (space group $\mathrm{n}^{\circ} 221, \mathrm{Z}=1$ ) crystal structure and represented along principal directions of the first BZ with irreducible representations of the double group. Middle panel: the very same band structure represented along principal directions of the first BZ of the orthorhombic Pnma unit cell (space group $\mathrm{n}^{\circ} 62, \mathrm{Z}=4$ ) evidencing the band folding from $R, M$ and $X$ to $\Gamma$, which results in an apparent 4-fold increase of the number of bands. Right panel: electronic band diagram calculated for the real low-temperature orthorhombic Pnma crystal structure shown along principal directions of its first BZ. It highlights effects of structural distortions on the band structure, namely the increased band-gap and the change in effective masses at VBM and CBM. Noteworthy, the band mixing remains moderate as a direct consequence of the large splitting of $\mathrm{CB}_{1,2}$ and $\mathrm{CB}_{3,6}$ (left panel) induced by $\mathrm{SOC}$ whereas such mixing would have been largely overestimated without soc.

This brings us to another theoretical issue that has been surprisingly overlooked for a long period of time: spin-orbit coupling (SOC). In fact, despite the energy diagram given by Tanaka et al. in 2003 that highlighted SOC band splitting at the $R$-edge of the cubic $\mathrm{BZ},{ }^{47}$ the fortuitous match between experimental optical band-gaps and DFT values most probably long obscured the need to take SOC into account, especially for lead-based perovskites. At least since 2012, the situation has improved both for 3D all-inorganic ${ }^{48,49}$ and 2D hybrid ${ }^{50}$ perovskites. The dramatic spin-orbit split-off of the conduction band (Figure 2) and its effect on optical properties (absorption strength and polarization) has been further demonstrated on 3D hybrids. ${ }^{30}$ Figure 2 also reveals the poor agreement between DFT + SOC calculated band-gaps $(<0.1 \mathrm{eV}$ for the Pm $\overline{3} \mathrm{~m}$ crystal structure) and experimental ones ( $c a 1.6 \mathrm{eV}$ ). In fact, the agreement obtained with values derived from bare ground state DFT is a direct consequence of accidental error compensation between SOC and many-body effects. In hybrid perovskites, this has first been shown by a one-shot GW correction on the DFT+SOC band-gaps of $\mathrm{CH}_{3} \mathrm{NH}_{3} \mathrm{PbI}_{3}{ }^{30}$ and $\mathrm{CH}_{3} \mathrm{NH}_{3} \mathrm{SnI}_{3}$, ${ }^{51}$ 
and was confirmed with an effective GW method incorporating SOC. ${ }^{52,53}$ The GW correction to the DFT ground state energies cures for charged excitations corresponding to the addition or removal of an electron. Besides, excitonic effects may further induce a disagreement between experimental and calculated optical properties. The later can be improved by implementing corrections based on the Bethe-Salpeter equations, ${ }^{51-55}$ but such an approach does not account for screening of the electron-hole interaction due to atomic/molecular motions, which has been suggested to dramatically reduce exciton binding energies in the high temperature phases of $\mathrm{CH}_{3} \mathrm{NH}_{3} \mathrm{PbX}_{3} .{ }^{56}$ Noteworthy, in 2D hybrids, excitons remain stable at room temperature (binding energies of a few hundreds of $\mathrm{meV})^{57}$ as a result of dielectric contrast between the organic and inorganic layers. Last, we may also stress that interplay between SOC and lack of centrosymmetry has been shown to lead to a $\boldsymbol{k}$-dependent band splitting in $3 \mathrm{D}$ hybrids $^{51}$ that may have potential applications in spintronics (so called Rashba-Dresselhaus effect $)^{45,53,58}$.

\section{Results and discussion}

Given the structural diversity of perovskites, illustrated Figure 3, we start to investigate metal substitution by considering $\mathrm{CH}_{3} \mathrm{NH}_{3} \mathrm{MCl}_{3}$, for $\mathrm{M}=\mathrm{Pb}, \mathrm{Sn}, \mathrm{Ge}$, in their reference cubic phases. We first stress that these high temperature phases exhibit an averaged disordered cubic phase (space group $\operatorname{Pm} \overline{3} \mathrm{~m}, \mathrm{Z}=1)$. The structural disorder is associated to the rotation of methylammonium cations, octahedral tilting as well as more complex octahedral distortions, especially for $\mathrm{M}=\mathrm{Ge}$ for which coordination is often described as pyramidal with $\mathrm{MCl}_{3}{ }^{-}$ions rather than octahedral. ${ }^{26}$ The calculated electronic band structures for these reference cubic phases shown Figure 4 reveal comparable dispersions along the principal directions of the first BZ for all three metals with a direct band gap at the Rpoint (vide supra). For $\mathrm{M}=\mathrm{Ge}$, one may notice reduced dispersion both in the $\mathrm{VB}$ and $\mathrm{CB}$ indicative of reduced hybridization between $\mathrm{Ge}(s)$ and $\mathrm{Cl}(p)$ orbitals and $\mathrm{Ge}(p)$ orbitals, respectively. Moreover, the $\mathrm{CB}$ states mainly build from $p$-like metal undergo a spin-orbit split-off between doubly degenerated $E_{1 / 2 u}$ and 4-fold degenerated $F_{3 / 2 u}$ states ${ }^{56}$ that decreases in going from $\mathrm{Pb}$ to $\mathrm{Sn}$ to $\mathrm{Ge}$. From atomic energy levels tables, and considering the expected +2 oxidation state of the metal/metalloid, the SOC splitting between the $p$-like orbitals of total angular momentum $\mathrm{J}=3 / 2$ and $\mathrm{J}=1 / 2$ amount to $1.75,0.53$ and $0.22 \mathrm{eV}$ for $\mathrm{Pb}^{2+}, \mathrm{Sn}^{2+}$ and $\mathrm{Ge}^{2+}$, respectively. ${ }^{59}$ Calculated band structures are consistent with these trends (Figure 4), with SOC splitting of $1.65,0.52$ and $0.22 \mathrm{eV}$, respectively. This splitting has a direct impact on the sequence of band-gaps along the series of metals, between the doubly degenerated $E_{1 / 2 \mathrm{~g}} \mathrm{VB}$ and $\mathrm{E}_{1 / 2 \mathrm{u}} \mathrm{CB}$ states at $\mathrm{R},{ }^{56}$ that undergoes full re-ordering upon inclusion of SOC (Table 1).

Optical absorption spectra computed from band-to-band transitions shown figure 5 further highlights SOC-induced changes, especially its effect on the intensity of the absorption, which directly affects the slope of optical absorption near the band-gap: the higher the SOC, the larger the reduction. Computed optical spectra also evidence the multivalley and multibangap nature, which has been shown to be the source of the broad light harvesting abilities of this family of perovskites, ${ }^{56}$ but with a larger energy gap between the primary absorption at $R$ and secondary transition at $M$ for chlorides as compared to iodides.

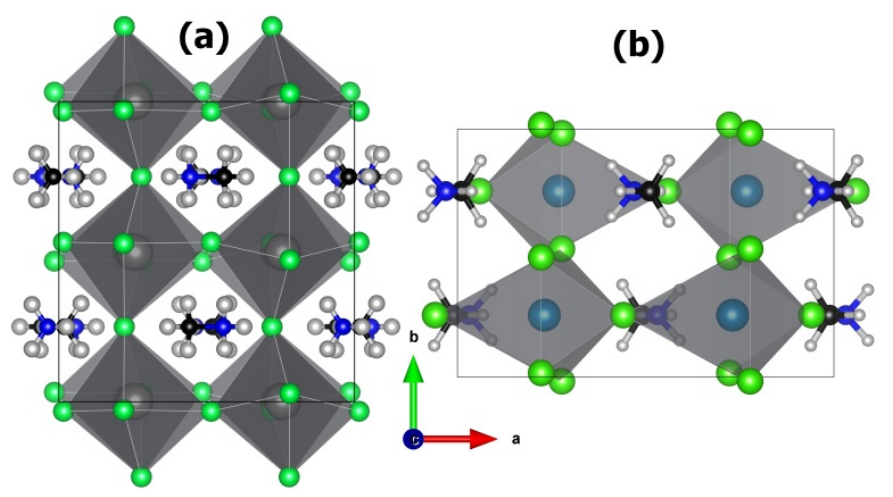

Fig. 3. Overview of the orthorhombic (Pnma) crystal structures of (a) $\mathrm{CH}_{3} \mathrm{NH}_{3} \mathrm{PbCl}_{3}$ at low temperature $(80 \mathrm{~K})^{24}$ and (b) $\mathrm{CH}_{3} \mathrm{NH}_{3} \mathrm{GeCl}_{3}$ at room temperature $(250 \mathrm{~K})^{22}$. The unit cell of $\mathrm{CH}_{3} \mathrm{NH}_{3} \mathrm{PbCl}_{3}$ is twice larger $(\mathrm{Z}=8)$ than that of $\mathrm{CH}_{3} \mathrm{NH}_{3} \mathrm{GeCl}_{3}$ $(\mathrm{Z}=4)$ and related low temperature phases of $\mathrm{CH}_{3} \mathrm{NH}_{3} \mathrm{Pbl}_{3}{ }^{26}$ and $\mathrm{CH}_{3} \mathrm{NH}_{3} \mathrm{PbBr}_{3}{ }^{25}$ and eight times larger than its room temperature disordered cubic phase $(P m \overline{3} m, Z=1){ }^{24,27}$ In addition to octahedral tilting, figure (b) highlights distortions that lead to pyramidal $\mathrm{GeCl}_{3}{ }^{-}$units.

Tab. I. Comparison between calculated electronic band-gaps at different levels of theory and available optical band-gaps measured at room temperature (RT) for $\mathrm{CH}_{3} \mathrm{NH}_{3} \mathrm{MCl}_{3}(\mathrm{M}=\mathrm{Pb}$, $\mathrm{Sn}, \mathrm{Ge})$. The RT space groups are in bold and band-gaps are given in eV.

\begin{tabular}{|c|c|c|c|c|c|c|c|}
\hline \multirow{2}{*}{$M$} & \multirow{2}{*}{$\begin{array}{l}\text { space } \\
\text { group }\end{array}$} & \multirow{2}{*}{$\begin{array}{c}T \\
(K)\end{array}$} & \multicolumn{2}{|c|}{ LDA } & \multicolumn{2}{|c|}{$\mathrm{PBE}(\mathrm{SOC}=0)$} & \multirow{2}{*}{ exp. } \\
\hline & & & $\mathrm{SOC}=0$ & $\mathrm{SOC} \neq 0$ & $\mathrm{G}_{0} \mathrm{~W}_{0}$ & GW & \\
\hline \multirow{2}{*}{$P b$} & $\mathrm{Pm} \overline{\mathbf{3}} \mathbf{m}$ & $>190$ & 1.81 & 0.62 & 3.7 & 3.4 & $3.1^{62}$ \\
\hline & Pnma & 80 & 2.32 & 1.25 & & & \\
\hline \multirow{2}{*}{ Sn } & $\mathrm{Pm} \overline{3} \mathrm{~m}$ & 478 & 1.17 & 0.82 & 2.5 & 2.2 & \\
\hline & Pc & 315 & 1.83 & 1.73 & $3.4^{63}$ & & $3.7^{63}$ \\
\hline \multirow{2}{*}{$G \epsilon$} & $\mathrm{Pm} \overline{3} \mathrm{~m}$ & 475 & 1.62 & 1.47 & 3.0 & 2.7 & \\
\hline & Pnma & 250 & 2.64 & 2.58 & & & \\
\hline
\end{tabular}

Besides, contrarily to $\mathrm{CH}_{3} \mathrm{NH}_{3} \mathrm{PbI}_{3}$, there is no fortuitous agreement between calculated LDA band-gaps and available experimental optical band-gaps, but in both cases the agreement worsens when SOC is included (Table 1). To illustrate qualitatively the importance of many-body effects in these chlorine-based hybrid perovskites, we performed $\mathrm{G}_{0} \mathrm{~W}_{0}{ }^{32}$ and self-consistent $\mathrm{GW}^{33}$ corrections starting with the GGA-PBE ${ }^{38}$ Kohn-Sham orbitals. The quasi-particle corrections to the bandgaps are large and in the opposite direction to SOC for all three metals, consistently with earlier findings for lead and tiniodides. ${ }^{30,51-55,60}$ As expected, calculated band-gaps become 
closer to experimental ones but differences remain sizeable, especially if one corrects for SOC afterwards. Moreover, the $\mathrm{G}_{0} \mathrm{~W}_{0}$ level leads to systematically larger corrections $(c a+0.3$ $\mathrm{eV}$ ) than self-consistent $\mathrm{GW}$, while an opposite trend has been reported for $\mathrm{CH}_{3} \mathrm{NH}_{3} \mathrm{PbI}_{3} .{ }^{60}$ Beyond illustrating the qualitative trends, these results emphasize the sensitivity of the GW corrections to several parameters that have recently been investigated by several groups in the context of hybrid perovskites. ${ }^{52-54,60}$ Among them, we first stress that in the present work, methylammonium cations have been replaced by $\mathrm{Cs}^{+}$to afford true $\mathrm{Pm} \overline{3} \mathrm{~m}$ symmetry. Many-body corrections are also sensitive to semi-core states, to SOC (non-additivity off SOC and GW) and to the starting Kohn-Sham orbitals. In addition, to reach quantitative agreement, excitonic effects and dynamical screening might be an issue,${ }^{56}$ but more importantly, the crystal structure in use should be relevant to the experimental conditions, ${ }^{51,53,54}$ e.g. RT Pc space phase for $\mathrm{M}=\mathrm{Sn}$.

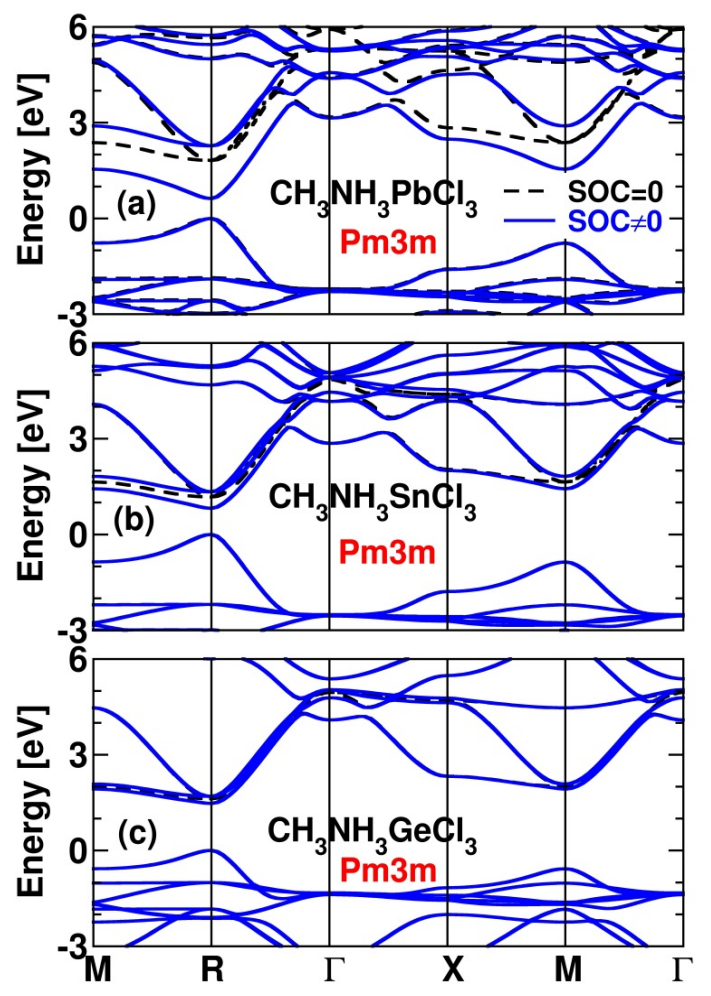

Fig. 4. Electronic band diagrams for the high temperature cubic phases (Pm $\overline{3} \mathrm{~m}$ ) of $\mathrm{CH}_{3} \mathrm{NH}_{3} \mathrm{MCl}_{3}$ : (a) $\mathrm{M}=\mathrm{Pb}$ (b) $\mathrm{M}=\mathrm{Sn}$ and (c) $\mathrm{M}=\mathrm{Ge}$, calculated at the LDA level of theory without (black dashed lines) and with (blue straight lines) SOC.

In fact, influence of crystal structure on band-gaps becomes obvious from calculated band-gaps reported Table 1 by comparing values obtained for the $\mathrm{Pm} \overline{3} \mathrm{~m}$ phases and the phases recorded at lower temperatures. First, a counterintuitive increase in band-gaps undergoes when decreasing the temperature as a result of phase transitions. Indeed, given the bonding and anti-bonding character of CBM and VBM, respectively, a shrinking of the unit cell with decreasing temperature should in turn reduce the band-gap. But, due to sizeable octahedral deformations (tilt and/or distortions, Table 2) CBM and VBM are destabilized and stabilized, respectively. Moreover, consistently with earlier findings on the model $\mathrm{CsPbI}_{3}$ system $^{45}$ such deformations have a direct impact on the strength of SOC leading to a three-fold reduction of SOC corrections to the band-gap for $\mathrm{M}=\mathrm{Sn}$ (Table 1 ), and expectedly on that of many-body effects as well. The computed band structure of the room temperature Pc phase of $\mathrm{CH}_{3} \mathrm{NH}_{3} \mathrm{SnCl}_{3}$ (Figure 6), when compared to that of the high temperature $\mathrm{Pm} \overline{3} \mathrm{~m}$ phase, further illustrates crystal structure implications on materials properties. First, it evidences partial band-folding as compared to the one shown Figure $2(Z=4)$ as a result of almost unchanged unit cell along the a-axis $(Z=2)$. Thus, the gap does not fold back to the BZ $\Gamma$-centre but to the $Y$-edge $(1 / 2,0,0)$ when SOC is overlooked. In addition, the gap becomes sizably indirect in the vicinity of $Y$, due to the interplay between SOC and lack of centrosymmetry. This evidences another example of the so-called Rashba-Dresselhaus effect (vide supra).
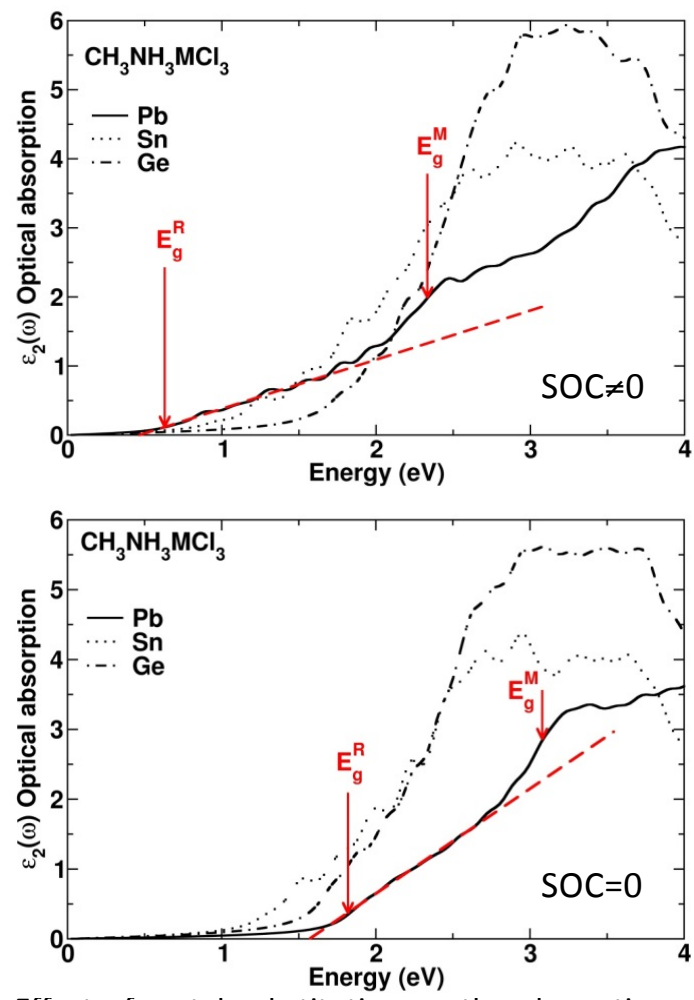

Fig. 5. Effect of metal substitution on the absorption spectra illustrated for $\mathrm{CH}_{3} \mathrm{NH}_{3} \mathrm{MCl}_{3}(\mathrm{M}=\mathrm{Pb}, \mathrm{Sn}, \mathrm{Ge})$ : Absorption spectra calculated with (top) and without (bottom) SOC for the high temperature cubic structures $(\mathrm{Pm} \overline{3} \mathrm{~m})$ of $\mathrm{CH}_{3} \mathrm{NH}_{3} \mathrm{MCl}_{3}(\mathrm{M}=\mathrm{Pb}$, $\mathrm{Sn}, \mathrm{Ge})$. Onsets of optical absorption at $\mathrm{R}$ and $\mathrm{M}$ are indicated for $\mathrm{CH}_{3} \mathrm{NH}_{3} \mathrm{PbCl}_{3}$.

Since Pnma is a centrosymmetric space group, such an SOC induced $\boldsymbol{k}$-dependent band splitting does not show up in the computed band structure of the low temperature phases of $\mathrm{CH}_{3} \mathrm{NH}_{3} \mathrm{PbCl}_{3}$ and $\mathrm{CH}_{3} \mathrm{NH}_{3} \mathrm{GeCl}_{3}$ for which the gap remains direct at the $\mathrm{BZ} \Gamma$-center (Figure 7). The apparent complex structure of their $\mathrm{CB}$ is related to symmetry breaking that leads 
both to an increase of the unit cell volume and strain. Symmetry analysis indicates that the $\mathrm{CB}$ electronic states at the $\Gamma$-point of the orthorhombic structure correspond to the triply degenerated states at the R-point (associated to the vectorial representation of the simple group, i.e. without SOC) of the $\mathrm{Pm} \overline{3} \mathrm{~m}$ cubic phase. ${ }^{30}$ For $\mathrm{M}=\mathrm{Pb}$, the spin-orbit split-off of the $\mathrm{CB}$ remains large and similar to the iodine-based analogue (Figure 2), with an $1.1 \mathrm{eV}$ correction to the LDA band-gap to be compared to $1.2 \mathrm{eV}$ for the cubic phase. Thus, it confirms that SOC induces larger changes than strain, while its strength is interrelated with structural deformations. SOC leads to a simplified structure of the CB that ensures applicability of effective mass approximations, especially for lead-based perovskites. ${ }^{30,50,51}$ Overall, the impact of $\mathrm{SOC}$ is similar for $\mathrm{M}=\mathrm{Ge}$, with the expected reduced strength, namely a $0.06 \mathrm{eV}$ SOC correction to the band-gap as compared to $0.15 \mathrm{eV}$ for the reference cubic phase (Table 1). Noteworthy, in the orthorhombic crystal structure of $\mathrm{CH}_{3} \mathrm{NH}_{3} \mathrm{GeCl}_{3}$ the coordination of $\mathrm{Ge}$ is clearly pyramidal with 3 short and 3 long bonds, ${ }^{26}$ alike that of $\mathrm{Sn}$ in its RT monoclinic phase (Table 2).

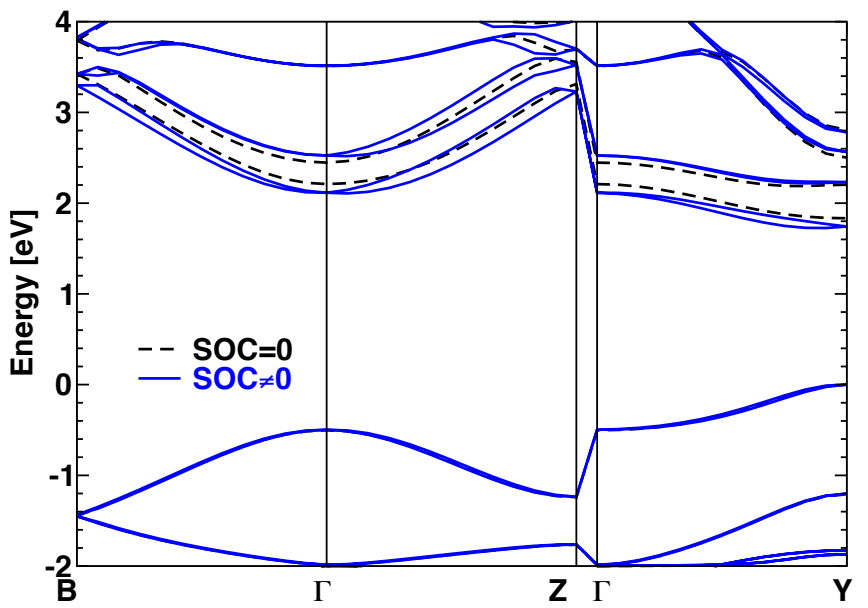

Fig. 6. Electronic band diagrams for the monoclinic (Pc) crystal structures of $\mathrm{CH}_{3} \mathrm{NH}_{3} \mathrm{SnCl}_{3}$ calculated at the LDA level of theory without (black dashed lines) and with (blue straight lines) SOC.

To investigate the SOC contributions stemming from halogens, Figure 8 shows band structure computed for $\mathrm{CH}_{3} \mathrm{NH}_{3} \mathrm{PbX}_{3}$ where SOC is switch on or off on the halide $\mathrm{X}=\mathrm{I}$, $\mathrm{Br}$ or $\mathrm{Cl}$. For chlorine, changes are almost vanishing but they increase down the halogen group (Table 3). SOC activated on iodine lead to a downward shift of $0.13 \mathrm{eV}$. These results are consistent with atomic energy levels tables. In fact, tacking the $n s^{2} n p^{5}$ electronic configuration of $\mathrm{X}=\mathrm{I}, \mathrm{Br}$ and $\mathrm{Cl}$, the $\mathrm{SOC}$ splitting between the $p$-like orbitals of total angular momentum $\mathrm{J}=3 / 2$ and $\mathrm{J}=1 / 2$ amount to $0.94,0.46$ and $0.11 \mathrm{eV} .{ }^{59}$ For fully negative ions $\mathrm{X}^{-}\left(n s^{2} n p^{6}\right.$ electronic configuration), such splitting would be vanishing as $\mathrm{J}=0$. Thus, this is also consistent with electronegativity of halogens that is known to decrease down the group (Allen scale: 2.87, 2.68, and 2.36 for $\mathrm{Cl}, \mathrm{Br}$ and I, respectively).

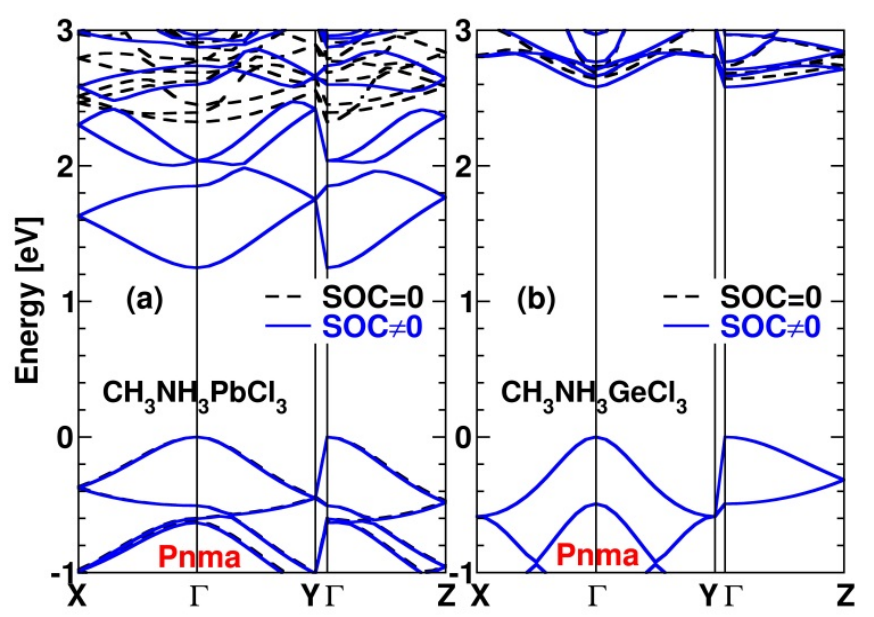

Fig. 7. Electronic band diagrams for the orthorhombic (Pnma) crystal structures shown Figure 3: (a) $\mathrm{CH}_{3} \mathrm{NH}_{3} \mathrm{PbCl}_{3}$ and (b) $\mathrm{CH}_{3} \mathrm{NH}_{3} \mathrm{GeCl}_{3}$, calculated at the LDA level of theory without (black dashed lines) and with (blue straight lines) SOC.

Tab. 2. Axial $d_{M-\mathrm{X}}^{a x}$ and equatorial $d_{M-\mathrm{X}}^{e q}$ metal-halide distances, equatorial angles $\mathrm{M}-\mathrm{X}-\mathrm{M}$ from crystallographic data recorded at various temperature $\mathrm{T}$ for $\mathrm{CH}_{3} \mathrm{NH}_{3} \mathrm{MCl}_{3}$ $(\mathrm{M}=\mathrm{Pb}, \mathrm{Sn}, \mathrm{Ge})$.

\begin{tabular}{|c|c|c|c|c|}
\hline & $\begin{array}{c}d_{M-X}^{e q} \\
(\AA ̊)\end{array}$ & $\begin{array}{c}d_{M-X}^{a x} \\
(\AA) \\
\end{array}$ & $\begin{array}{c}\text { M-X-M } \\
\text { (degree) }\end{array}$ & $\begin{array}{c}\mathrm{T} \\
(K)\end{array}$ \\
\hline $\begin{array}{c}\mathrm{CH}_{3} \mathrm{NH}_{3} \mathrm{PbCl}_{3} \\
\mathrm{Pm} 3 \mathrm{~m}\end{array}$ & 2.84 & 2.84 & 180 & $>190$ \\
\hline $\begin{array}{c}\mathrm{CH}_{3} \mathrm{NH}_{3} \mathrm{PbCl}_{3} \\
\text { Pnma }\end{array}$ & $\begin{array}{l}2.88 \\
2.72 \\
2.83 \\
3.02\end{array}$ & $\begin{array}{l}2.87 \\
2.85\end{array}$ & $\begin{array}{l}(a c) \\
155 \\
161 \\
(a b) \\
164\end{array}$ & 80 \\
\hline $\begin{array}{c}\mathrm{CH}_{3} \mathrm{NH}_{3} \mathrm{SnCl}_{3} \\
\mathrm{Pm} 3 \mathrm{~m}\end{array}$ & 2.88 & 2.88 & 180 & 478 \\
\hline $\begin{array}{c}\mathrm{CH}_{3} \mathrm{NH}_{3} \mathrm{SnCl}_{3} \\
\mathrm{PC}\end{array}$ & $\begin{array}{l}3.17 \\
2.60 \\
\end{array}$ & $\begin{array}{l}3.06 \\
2.69 \\
\end{array}$ & $\begin{array}{l}163 \\
166 \\
\end{array}$ & 315 \\
\hline $\begin{array}{c}\mathrm{CH}_{3} \mathrm{NH}_{3} \mathrm{GeCl}_{3} \\
\mathrm{Pm} 3 \mathrm{~m}\end{array}$ & 2.85 & 2.85 & 180 & 475 \\
\hline $\begin{array}{c}\mathrm{CH}_{3} \mathrm{NH}_{3} \mathrm{GeCl}_{3} \\
\text { Pnma }\end{array}$ & $\begin{array}{l}3.29 \\
2.32\end{array}$ & $\begin{array}{l}3.27 \\
2.34\end{array}$ & $\begin{array}{l}164 \\
168\end{array}$ & 250 \\
\hline
\end{tabular}

This brings us to the charge concept of an atom that is not based on physically measurable quantities, but subjected to space partitioning. Among the various ways to derive atomic charges in molecules or solids, the quantum theory of atoms in molecules (AIM) ${ }^{34}$ affords unambiguous atomic boundary from any electron density, experimental or computed. ${ }^{61}$ Therefore, we have computed AIM charges for a couple of the crystal structures investigated in this work. First of all, AIM charges little depend on the investigated crystalline phase, as illustrated with the Pnma and $\mathrm{Pm} \overline{3} \mathrm{~m}$ phases of $\mathrm{CH}_{3} \mathrm{NH}_{3} \mathrm{GeCl}_{3}$ for which $\mathrm{Ge}$ has a constant charge nearest one-hundredth. When changing the halogen from $\mathrm{Cl}$ to $\mathrm{I}$, in the Pnma phases of $\mathrm{CH}_{3} \mathrm{NH}_{3} \mathrm{PbX}_{3}$, the halogen negative charge drops from 0.68 to 
0.54 , consistently with their respective electronegativity (vide supra). The combined effect of reduced $n s^{2} n p^{5}$ character, with respect to $n s^{2} n p^{6}$, and reduced atomic SOC splitting, for $\mathrm{Cl}$ as compared to I, both contribute to reduced halogen induced SOC (Table 3). Concomitantly, the positive charge of $\mathrm{Pb}$ decreases from 1.24 to 0.90 , maintaining an almost constant charge transfer with the organic cation ( 0.79 and 0.73 , respectively). This decrease of the positive charge of $\mathrm{Pb}$ results in a smaller SOC split-off of the CB in $\mathrm{MAPbI}_{3}$ as compared to $\mathrm{MAPbCl}_{3}$, and in turn to a smaller SOC correction of the band gap (see Table S1 of ref. [56]). Metal substitution, investigated for the reference cubic phases of $\mathrm{CH}_{3} \mathrm{NH}_{3} \mathrm{MCl}_{3}$, reveals nonmonotonic trends of metal positive charges, which amount to $1.15,1.21$ and 1.05 for $\mathrm{Pb}, \mathrm{Sn}$ and $\mathrm{Ge}$, respectively. This correlates nicely with their ionization energies amounting to 716, 709 and $762 \mathrm{~kJ} / \mathrm{mol}^{59}$ At the same time, the AIM charge of $\mathrm{Cl}$ changes so as to maintain a 0.9 charge transfer between $\mathrm{MX}_{3}$ anions and the $\mathrm{Cs}$ cation introduced to mimic $\mathrm{CH}_{3} \mathrm{NH}_{3}$. Besides, given the large atomic SOC splittings and the good correlation with the SOC split-off extracted from the calculated band structure of $\mathrm{CH}_{3} \mathrm{NH}_{3} \mathrm{MCl}_{3}$, for $\mathrm{M}=\mathrm{Pb}, \mathrm{Sn}$ and $\mathrm{Ge}$, (vide supra) the slight changes of metal/metalloid AIM atomic charges can hardly be discussed in relation to SOC.

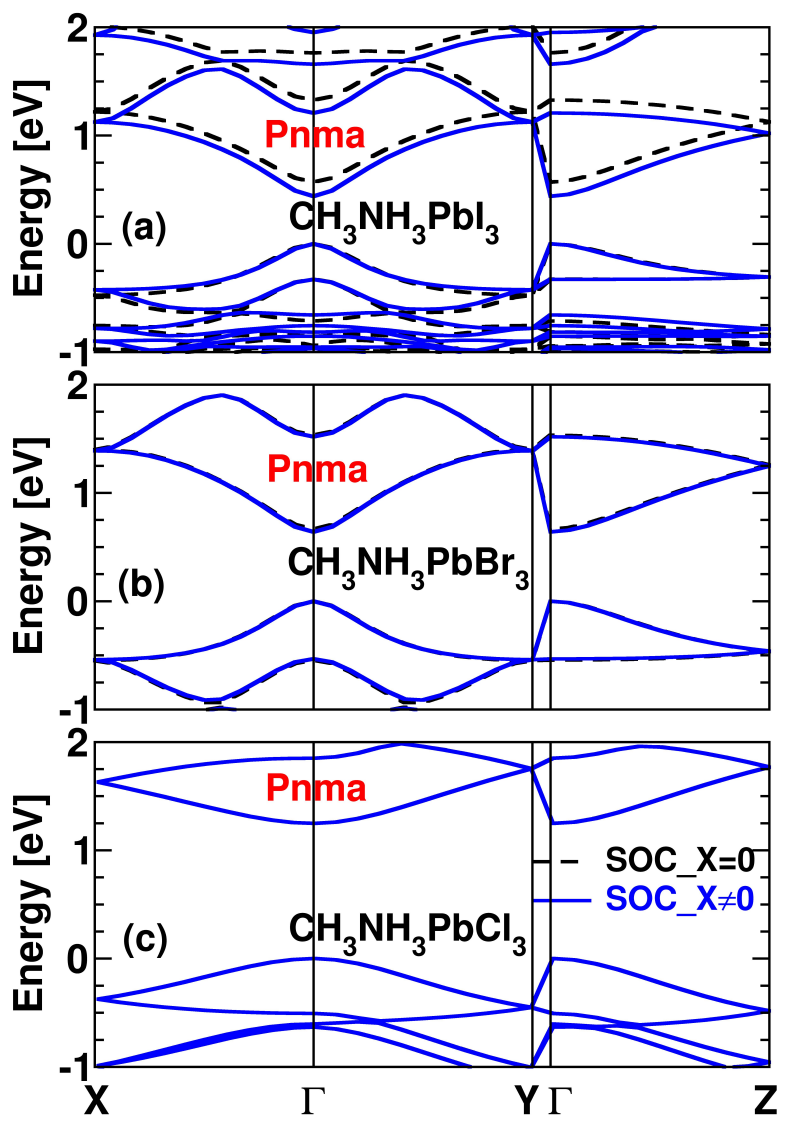

Fig. 8. Electronic band diagrams for the orthorhombic phases (Pnma) of (a) $\mathrm{CH}_{3} \mathrm{NH}_{3} \mathrm{Pbl}_{3}$, (b) $\mathrm{CH}_{3} \mathrm{NH}_{3} \mathrm{PbBr}_{3}$ and (c) $\mathrm{CH}_{3} \mathrm{NH}_{3} \mathrm{PbCl}_{3}$, calculated at the LDA level of theory with SOC always taken into account for $\mathrm{Pb}$ atoms and switch off (black dashed lines) and on (blue straight lines) for the halogens.
Tab. 3. Computed electronic band-gaps (eV) for the orthorhombic Pnma structures of $\mathrm{CH}_{3} \mathrm{NH}_{3} \mathrm{PbX}_{3}(\mathrm{X}=\mathrm{I}, \mathrm{Br}, \mathrm{Cl})$ at the LDA level of theory with SOC always taken into account for $\mathrm{Pb}$ atoms and switch off and on for the halogens.

\begin{tabular}{c|l|l|l}
\hline$x$ & $\mathrm{l}$ & $\mathrm{Br}$ & $\mathrm{Cl}$ \\
\hline SOC $=$ off & 0.569 & 0.664 & 1.248 \\
\hline SOC=on & 0.437 & 0.639 & 1.248 \\
\hline$\Delta_{\text {SOC }}^{X}$ & 0.132 & 0.025 & 0.000
\end{tabular}

\section{Conclusions}

First, let us start with a quite basic comment and stress that independently of the option taken for the exchange-correlation potential, bare DFT is a ground state theory. As such, DFT calculated band-gaps are not expected to agree with experimental optical band-gaps, even when turning to last generation kernels such as range separated hybrids or dispersion-corrected functionals. For hybrid perovskites (as well as all-inorganic perovskites) spin-orbit coupling and many-body effects are of paramount importance to achieve an accurate description of the physical properties. Moreover, the crystal structure should also be relevant to the operating conditions of devices. This is further highlighted in the present work where impact of metal substitution has also been discussed.

Our theoretical investigation on the tri-chlorides $\mathrm{CH}_{3} \mathrm{NH}_{3} \mathrm{MCl}_{3} \quad(\mathrm{M}=\mathrm{Pb}, \mathrm{Sn}, \mathrm{Ge})$ leads to SOC splittings consistent with atomic energy levels tables with an increase down the group-14 of the periodic table. The structure of the relevant conduction bands is less complex than that obtained without SOC. This also holds for germanium-based perovskites for which SOC remains sizable. As a consequence, simpler models can be used such as those based on the effective mass approximation. However, from the different crystal structures studied and from comparison to available experimental bandgaps, we confirm the subtle interplay between SOC, many-body effects and structural distortions. This leads to non-additive "corrections" to the band structure and in turn to the band-gap. In addition, SOC interactions stemming from halogens are shown to be sizable, especially for iodine-based perovskites, consistently with atomic data and computed AIM atomic charges.

As far as devices are concerned, it is clear that the chloridebased perovskites with experimental band gaps larger that $3 \mathrm{eV}$ are unsuited for $\mathrm{PV}$ technologies based on pure materials. However, the used of metal alloys, i.e. $\mathrm{CH}_{3} \mathrm{NH}_{3} \mathrm{PbI}_{3-\mathrm{x}} \mathrm{Cl}_{\mathrm{x}}$, affords additional degrees of freedom for band-gap tuning. In addition, let us point out that large band-gap hybrid perovskites may find applications for solar cells in multijunctions devices, where light harvesting is optimized through the entire solar spectrum. Chlorine-based hybrid perovskites may thus provide large band-gap layers for top cell in multijunction heterostructures. Finally, chlorine-based perovskites may also be interesting for band gap tuning in light-emitting diodes or lasers. $^{15-17}$ 


\section{Acknowledgements}

The authors gratefully acknowledge Dr. Karine Costuas for useful discussions. This work was performed using HPC resources from GENCI/CINES/TGCC/IDRIS grant 2014 x2014096724. The work was supported by Agence Nationale pour la Recherche (PEROCAI project ANR1004) as well as the CNRS (PEPS ENERGIE 2014 SOLHYBTRANS).

\section{Corresponding author}

Electronic mail: claudine.katan@univ-rennes1.fr; jacky.even@insarennes.fr

\section{Notes and references}

${ }^{a}$ Institut des sciences chimiques de Rennes, CNRS - Université de Rennes 1, UMR6226, 35042 Rennes, France. E-mail: claudine.katan@univ-rennes1.fr

${ }^{b}$ Université Européenne de Bretagne, FOTON, INSA de Rennes - CNRS, UMR 6082, 35708 Rennes, France. E-mail: jacky.even@insa-rennes.fr

1 T. Leijtens, G. E. Eperon, S. Pathak, Sandeep A. AbateM. M. Lee, H. J. Snaith, Nat. Comm. 2013, 4, 2885.

2 P.-Y. Chen, J. Qi, M. T. Klug, X. Dang, P. T. Hammond, A. M. Belcher, Energy Environ. Sci., 2014, 7, 3659-3665.

3 Y. Ogomi, A. Morita, S. Tsukamoto, T. Saitho, N. Fujikawa, Q. Shen, T. Toyoda, K. Yoshino, S. S. Pandey, T. Ma and S. Hayase, J. Phys. Chem. Lett., 2014, 1004-1011.

4 C. C. Stoumpos, C. D. Malliakas, M. G. Kanatzidis, Inorg. Chem., 2013, 52, 9019-9038.

5 G. C. Papavassiliou, Prog. Solid St. Chem., 1997, 25, 125-270.

6 D. B. Mitzi, J. Chem. Soc., Dalton Trans., 2001, 1, 1-12.

7 N. Mercier, N. Louvain, W.H. Bi, CrystEngComm, 2009, 11, 720734.

8 C. Smith, E. T. Hoke, D. Solis-Ibarra, M. D. McGehee, H. I. Karunadasa, Angew. Chem. Int. Ed. 2014, 53, $11232-11235$.

9 D. B. Mitzi, S. Wang, C. A. Field, C. A. Chess and A. M. Guloy, Science, 1995, 267, 1473-1476.

10 C. R. Kagan, D. B. Mitzi and C. D. Dimitrakopoulos, Science, 1999, 286, 945-947.

11 J. Wenus, R. Parashkov, S. Ceccarelli, E. Bréhier, J.-S Lauret, M. S. Skolnick,. E. Deleporte, D. G. Lidzey, Phys. Rev. B, 2006, 74, 235212-235217.

12 I. Koutselas, P. Bampoulis, E. Maratou, T. Evagelinou, G. Pagona, G. C. Papavassiliou, J. Phys. Chem. C, 2011, 115, 8475-8483

13 G. C. Papavassiliou, G. Pagona, N. Karousis, G. A. Mousdis, I. Koutselas, A. Vassilakopoulou, Mater. Chem., 2012, 22, 8271-8280.

14 G. C. Papavassiliou, G. A. Mousdis, G. Pagona, N. Karousis, M.-S. Vidali, J. of Luminescence, 2014, 14, 287-291.

15 Z.K.Tan R.S. Moghaddam, M.L Lai, P. Docampo, R Higler, F. Deschler, M. Price,.A. Sadhanala, L.M.Pazos, D. Credgington, F. Hanusch, T. Bein, H. J. Snaith, R.H. Friend, Nature Nanotech., 2014 , 9, 687-692.

16 F. Deschler, M. Price, S. Pathak, L. E. Klintberg, D.-D. Jarausch, R. Higler, S. Hüttner, T. Leijtens, S. D. Stranks, H. J. Snaith, M. Atatüre, R. T. Phillips, R. H. Friend, J. Phys. Chem. Lett., 2014, 5, $1421-1426$.
17 G. Xing, N. Mathews, S. M. Lim, N. Yantara, X. Liu, D. Sabba, M. Grätzel, S. Mhaisalkar, T. C. Sum, Nature Mat. 2014, 13, 476-480.

18 G. C. Papavassiliou, I. B. Koutselas, A. Terzis, M.-H. Whangbo, Solid State Comm., 1994, 91, 695-698.

19 J. L. Knutson, J. D. Martin, D. B. Mitzi, Inorg. Chem. 2005, 44, 4699-4705.

20 J. Even, L. Pedesseau, C. Katan, Proceedings of SPIE, 2014, 9140, 91400Y.

21 F. H. Allen, Acta Cryst., B, 2002, 58, 380-388.

22 K. Yamada, K. Mikawa, T. Okuda and K. S. Knight, J. Chem. Soc. Dalton Trans., 2002, 10, 2112-2118.

23 K. Yamada, Y. Kuranaga, K. Ueda, S. Goto, T. Okuda, and Y. Furukawa, Bull. Chem. Soc. Jpn., 1998, 71, 127-134.

24 L. Chi, I. Swainson, L. Cranswicka, J.-H. Herb, P. Stephens, O. Knop, J. Solid State Chem., 2005, 178, 1376-1385.

25 I. P.Swainson, R. P.Hammond, C. Soulliere, O. Knop, W. Massa, J. Solid State Chem., 2003, 176, 97-104.

26 T. Baikie, Y. Fang, J. M. Kadro, M. Schreyer, F. Wei, S. G. Mhaisalkar, M. Graetzel and T. J. White, J. Mater. Chem. A., 2013, 1, 5628-5641.

27 A. Poglitsch, D. Weber, J. Chem. Phys., 1987, 87, 6373-6378.

28 X. Gonze, B. Amadon, P. M. Anglade, J. M. Beuken, F. Bottin, P. Boulanger, F. Bruneval, D. Caliste, R. Caracas, M. Cote, T. Deutsch, L. Genovese, Ph. Ghosez, M. Giantomassi, S. Goedecker, D.R. Hamann, P. Hermet, F. Jollet, G. Jomard, S. Leroux, M. Mancini, S. Mazevet, M.J.T. Oliveira, G. Onida, Y. Pouillon, T. Rangel, G.-M. Rignanese, D. Sangalli, R. Shaltaf, M. Torrent, M.J. Verstraete, G. Zerah, J.W. Zwanziger, Comp. Phys. Comm., 2009, 180, 2582-2615.

29 C. Hartwigsen, S. Goedecker, J. Hutter, Phys. Rev. B, 1998, 58, 3641 3662 .

30 J. Even, L. Pedesseau, J M. Jancu, C. Katan, J. Phys. Chem. Lett., 2013, 4, 2999-3005.

31 L. Pedesseau, J. M. Jancu, A. Rolland, E. Deleporte, C. Katan, J. Even, Opt. Quant. Electron., 2014, doi: 10.1007/s11082-013-9823-9.

32 M. Shishkin, G. Kresse, Phys. Rev. B, 2006, 74, 035101.

33 M. Shishkin, G. Kresse, Phys. Rev. B, 2007, 75, 235102.

34 R. F. W. Bader, Atoms in Molecules: a Quantum Theory. The International Series of Monographs on Chemistry. 1990, Oxford: Clarendon Press.

35 C. Katan, P. Rabiller, C. Lecomte, M. Guezo, V. Oison, M. Souhassou, J. Appl. Crystallogr., 2003, 36, 65-73.

36 G. Kresse and J. Furthmüller, Comput. Mat. Sci., 1996, 6, 15-50.

37 P. E. Blöchl, Phys.Rev.B, 1994, 50, 17953-17979.

38 J. P. Perdew, K. Burke and M. Ernzerhof, Phys. Rev. Lett., 1996, 77, 3865-3868.

39 Y. Y. Li, C. K. Lin, G. L. Zheng, Z. Y. Cheng, H. You, W. D. Wang, J. Lin, Chem. Mater., 2006, 18, 3463-3469.

40 T. Umebayashi, K. Asai, T. Kondo, A. Nakao, Phys.Rev.B, 2003, 67, 155405.

41 S. Sourisseau, N. Louvain, W. Bi, N. Mercier, D. Rondeau, F. Boucher, J.-Y. Buzaré, C. Legein, Chem. Mater., 2007, 19, 600-607.

42 I. P. Swainson, Acta Cryst. B, 2005, 61, 616-626.

43 R. Tamazian, S. van Smaalen, Acta Cryst. B, 2007, 63, 190-200.

44 P. Garcia-Fernandez, J. A. Aramburu, M. T. Barriuso, M. J. Moreno, Phys. Chem. Lett., 2010, 1, 647-651. 
45 A. Amat, E. Mosconi, E. Ronca, C. Quarti, P. Umari, Md. K. Nazeeruddin, M. Grätzel, F. De Angelis, Nano Lett., 2014, 14, 36083616.

46 I. Borriello, G. Cantele, D. Ninno, Phys. Rev. B, 2008, 77, 235214.

47 K. Tanaka, T. Takahashi, T. Ban, T. Kondo, K. Uchida, N. Miura, Solid State Commun., 2003, 127, 619-623.

48 I. Chung, J-H Song, J. Im, J. Androulakis, C. D. Malliakas, H. Li, A. J. Freeman, J. T. Kenney and M. G. Kanatzidis, J. Am. Chem. Soc., 2012, 134, 8579-8587.

49 H. Jin, J. Im, A. J. Freeman, Phys.Rev.B, 2012, 86, 121102.

50 J. Even, L. Pedesseau, M. A. Dupertuis, J. M. Jancu and C. Katan, Phys. Rev. B., 2012, 86, 205301.

51 J. Even, L. Pedesseau, J. M. Jancu and C. Katan, Phys. Status Solidi $R R L, 2014,8,31-35$.

52 P. Umari, E. Mosconi and F. De Angelis, Sci. Rep., 2014, 4, 4467.

53 F. Brivio, K. T. Butler, A. Walsh, M. van Schilfgaarde, Phys. Rev. B, 2014, 89, 155204.

54 E. Menéndez-Proupin, P. Palacios, P. Wahnón, and J. C. Conesa, Phys. Rev. B, 2014, 90, 045207.

55 X. Zhu, H. Su, R. A. Marcus, . M. E. Michel-Beyerle, J. Phys. Chem. Lett., 2014, 5, 3061-3065.

56 J. Even, L. Pedesseau, C. Katan, J. Phys. Chem. C, 2014, 118, 11566-11572.

57 T. Ishihara, J. Takahashi, T.i Goto, Phys. Rev. B, 1990, 42, 1109911107.

58 M. Kim, J. Im, A. J. Freeman, J. Ihm, H. Jin, Proc. Natl. Acad. Sci. U.S.A., 2014, 111, 6900-6904.

59 A. Kramida, Y. Ralchenko, J. Reader, and NIST ASD Team (2014). NIST Atomic Spectra Database (ver. 5.2), [Online]. Available: http://physics.nist.gov/asd [2014, September 14]. National Institute of Standards and Technology, Gaithersburg, MD.

60 M. R. Filip, G. E. Eperon, H. J. Snaith, F. Giustino, Nat. Comm. 2014, 5, 5757.

61 P. Garcia, S. Dahaoui, C. Katan, M. Souhassou, C. Lecomte, Faraday Discuss., 2007, 135, 217-235.

62 N. Kitazawa, Y. Watanabe, Y. Nakamura, J. Mat. Sci.,2002, 37, 3585-3587.

63 F. Chiarella, A. Zappettini, F. Licci, Phys. Rev. B, 2008, 77, 045129. 

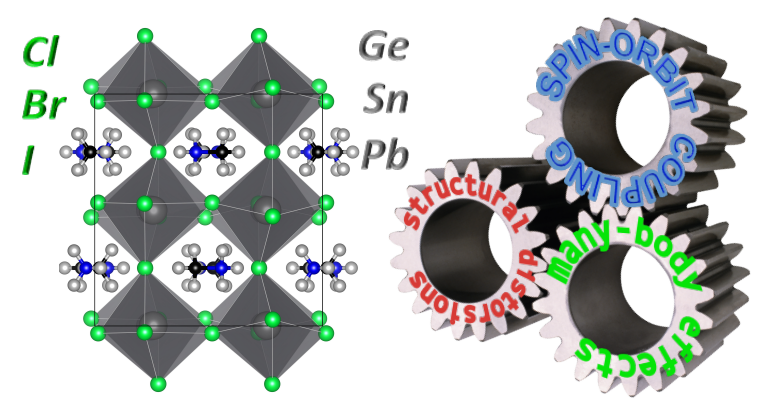

Metal and halogen substitution in hybrid perovskites reveal interplay between spin-orbit coupling, structural distortions and many-body effects controlling band-gaps

J. Mater. Chem. A, 2015, 3, 9232-9240; DOI: 10.1039/C4TA06418F 